$$
\begin{array}{lrr}
\text { STUDIA } & \text { ROMANICA } & \text { POSNANIENSIA } \\
\hline \text { UAM } & \text { Vol. 29 } & \text { Poznani 2003 }
\end{array}
$$

WIACZESŁAW NOWIKOW

Universidad Adam Mickiewicz, Poznań

\title{
SOBRE LAS PROPIEDADES TEMPORALES Y ASPECTUALES: EL PRETÉRITO EN LA CONSTRUCCIÓN ESTAR + GERUNDIO
}

\begin{abstract}
A b st r a c t. Nowikow Wiaczesław, Sobre las propiedades temporales y aspectuales: el pretérito en la construcción "estar" + gerundio [About temporal and aspectual properties: the Preterite in the construction estar + gerund]. Studia Romanica Posnaniensia, Adam Mickiewicz University Press, Poznań, vol. XXIX: 2003, pp. 197-204, ISBN 83-232-1232-5, ISSN 0137-2475.
\end{abstract}

The paper presents the different questions related to the grammatical status of the construction "ester" + gerund (está cantando) in the modern Spanish language. The author concentrates with special attention on the use of Preterite in the a.m. construction (estuvo cantando) and on the distinction between temporal and aspectual properties in the description of this paraphrase. In particular, the most important property of estuvo cantando is the expression of the actions 'in course', but, at the same time, 'limited in time'.

\section{EL ORIGEN DE LA CONSTRUCCIÓN}

Como es sabido, la perífrasis estar + gerundio, ausente en la mayoría de las lenguas romances, constituye una particularidad morfosintáctica del español moderno. Así, p.ej., en francés su equivalente suele ser la expresión être en train de + infinitivo (véase los datos que proporciona a este respecto el trabajo de Nowosadko, 2000), mientras que en el portugués peninsular la perífrasis en cuestión ha sido reemplazada por la construcción estar a + infinitivo (Neustroeva, 1997: 153). En cambio, varios autores (véase, p. ej., Sławomirski, 1983: 105-106) seńalan tanto semejanzas (p. ej., el valor "progresivo") como diferencias de la perífrasis espańola con respecto a los tiempos "continuos" del inglés (to be + -ing: I am reading) destacando el carácter optativo de la construcción castellana, así como la imposibilidad de la autoauxiliación del verbo estar (*está estando loca).

El origen de la perífrasis se remonta a la época de la transición del latín tardío al romance hispánico y se ve relacionado con dos hechos (cf. a este respecto, p. ej., Vasil'eva-Švede, Stepanov, 1972: 206-207, 283-284 y Fernández Laguinilla, 1999: 3453): 
a) con la confluencia del ablativo del gerundio y del participio presente activo latinos al desempeńar la función del complemento circunstancial (hominem video legendo) el primero, y la del complemento modificador el segundo (hominem legentem video), desarrollándose en ambos casos el proceso de adverbialización de la acción, y

b) con la gramatización paulatina de la construcción estar (< stare) + gerundio en la modalidad hablada del romance penithsular.

De modo que ya en el siglo XII en el Cantar de Mio Cid es posible documentar varios ejemplos en los cuales el gerundio forma parte de las perífrasis con los verbos se(e)r y estar, lo que se comprueba en la primera oración conservada de la famosa obra:

De los sos ojos tan fuertemientre llorando

tornava la cabę̧a $i$ estávalos catando.

\section{EL STATUS GRAMATICAL}

El valor gramatical de la construcción estar + gerundio suele ser establecido por varios lingüístas a partir de las características temporales y aspectuales, siendo éstas, propias de toda la perífrasis o de los elementos que la integran.

Desde la perspectiva temporal, la construcción en cuestión denota acciones simultáneas respecto al origen o a algún punto anterior o posterior a éste. El rasgo de simultaneidad es inherente al valor gramatical del gerundio que habitualmente indica acciones del tipo secundario que acompañan a otras, cuyo carácter es primario $^{1}$. Cabe señalar que en muchos casos, sobre todo cuando se trata de los verbos semánticamente permanentes (leer, escribir, vivir, etc.), el carácter simultáneo de la acción puede ser percibido al mismo tiempo como durativo, v. g., Puedes hacerlo perfectamente bien viviendo en esta ciudad, lo que permite a varios autores matizar el valor del gerundio en términos aspectuales (véase, p. ej., Fernández Laguinilla, ibíd.: 3456-3457 o Vasil'eva-Švede, Stepanov, ibíd.: 207$208,286)^{2}$.

\footnotetext{
${ }^{1}$ Cf. con este motivo los ejemplos de Rojo, Veiga (1999: 2880):

Cuando llegamos a la estación, había dos hombres esperândonos.

Cuando lleguemos a la estación, habrá dos hombres esperándonos.
}

En el primer caso la forma del gerundio seńala una acción simultánea a una referencia anterior al origen mientras que en el segundo, lo hace respecto a un punto posterior a éste.

${ }^{2}$ Notemos que la expresión de duración demuestra una dependencia evidente de las propiedades semánticas del verbo, es decir, si éste es desinente, p. ej., Puedes decírmelo entrando en el edificio, la acción marcada por el gerundio no tiene carácter expresamente durativo, aunque, desde una perspectiva pragmática, la acción de entrar no siempre es puntual o momentánea. Esto justifica las posibles extensiones semántico-pragmáticas en el caso de los verbos semánticamente desinentes. Cabe recordar 
De acuerdo con este último planteamiento, el gerundio funciona como marca de duración o de imperfectividad, factor que al entrar en combinación con la "estatividad" semántica del verbo estar, contribuye a que el valor gramatical de la construcción se considere como no cursivo y prototípicamente durativo (Sedano, 2000: 254, 258). Algunos autores incluso postulan que la perífrasis estar + gerundio actúa en el español moderno como unidad portadora del aspecto imperfectivo. Así, Vasil'eva-Švede y Stepanov (op. cit.: 212, 222) le ponen etiqueta de 'forma continua' señalando que ésta, siendo exponente de imperfectividad, establece dos oposiciones: la primera con respecto a las formas aspectualmente neutrales (canto, he cantado y los demás "tiempos simples y compuestos") y la segunda, con referencia a la construcción aspectualmente perfectiva tener + participio del verbo transitivo (tengo escrita la carta) ${ }^{3}$.

Por otro lado, los autores señalados al postular el reconocimiento de estar + gerundio como marca del aspecto imperfectivo, apuntan al mismo tiempo (ibíd.: 213) que en realidad se trata de una forma tempo-aspectual mediante la cual la duración de la acción se presenta como un fenómeno bidimensional. La inseparabilidad de los dos factores ha sido seńalada también por Yllera (1999: 3402) al opinar que la perífrasis denota acciones en desarrollo y en curso coincidentes con un lapso temporal situado, según el tiempo del verbo auxiliar, en el presente, en el futuro o en el pasado.

Dicha dualidad conceptual se explica, por una parte, por la contigüidad gramatical de las nociones de simultaneidad e imperfectividad (fijémonos que en polaco y en ruso, lenguas con aspecto expresado morfológicamente, la imperfectividad es compatible con la simultaneidad al origen, mientras que no ocurre lo mismo con la perfectividad) y, por otra, por el carácter ambiguo del concepto y del término 'duración' que se refiere tanto al tiempo de durar algo (la crisis va a durar mucho tiempo) como a la propia acción de durar (los problemas relacionados con la duración de la crisis son muy graves). Si 'simultaneidad' e 'imperfectividad' son conceptos, respectivamente, temporal y aspectual, la noción de 'duración' ocupa, de hecho, una posición intermedia.

Sin entrar en detalles, creemos que el rasgo de 'imperfectividad' debería ser explicado a partir de la característica de 'simultaneidad'. No cabe duda de que el valor gramatical de la perífrasis estar + gerundio habría que establecerlo de acuerdo

que en las lenguas que poseen el aspecto como categoría morfologica, el aktionsart del tipo terminativo no impide que ya a nivel de infinitivo existan dos formas aspectualmente distintas. Por ejemplo, al verbo espanol entrar, en polaco y en ruso le corresponden dos formas diferentes: una, de aspecto imperfectivo (pol. wchodzić, r. wchodit'), para expresar acciones no concluidas y otra, de aspecto perfectivo, para marcar la realización completa del acto (pol. wejść, r. wojti). Esto quiere decir que si el sistema dispone de determinados recursos linguísticos, una acción semánticamente desinente (limitada) puede ser presentada como imperfectiva (inconclusa).

${ }^{3}$ A diferencia de estos autores, Slawomirski (op. cit.: 106) opina que la construcción estar + gerundio no forma parte de la oposición aspectual y pertenece a uno de los tipos del Aktionsart. 
con los principios generales en torno a los cuales está organizado el sistema del verbo español. Las bases estructurales de este sistema, entre otros por la ausencia del aspecto morfologico, son claramente temporales. No obstante, como hemos señalado supra, hay factores que posibilitan la interpretación del funcionamiento de la construcción estar + gerundio en términos aspectuales, lo que no quiere decir que se trate de un caso de manifestación de la categoría gramatical de aspecto.

\section{EL TIEMPO DEL VERBO AUXILIAR}

En su estudio sociolinguíístico Sedano (op. cit.: 258) entre diferentes variables sometidas a la investigación (tipo de sujeto, negación, semántica del verbo en gerundio, etc.) menciona la de modo y tiempo del verbo estar. La mayoria de los autores (véase, p. ej., los trabajos citados de Vasil'eva-Švede, Stepanov, 1972: 215 y de Yllera, 1999: 3405) señala que la perífrasis se construye habitualmente con el presente y con el copretérito (imperfecto) de indicativo. Cabe subrayar que el vector temporal primario de estas formas es el de simultaneidad ${ }^{4}$. Es de notar que en el corpus de Caracas analizado por Sedano (op. cit.: 263-264) el porcentaje de estälestaba cantando constituye el $92 \%$ del total de los casos registrados.

No obstante, el verbo auxiliar estar puede darse prácticamente en todos los tiempos verbales y, entre éstos, en forma del pretérito ${ }^{5}$.

\section{EL VALOR GRAMATICAL DE ESTUVO CANTANDO}

El análisis de los ejemplos procedentes de los estudios de Vasil'eva-Švede, Stepanov (1972), Yllera (1999) y Nowosadko (2000) hace patente que casi en todos los casos el uso de estuvo cantando se ve acompańado por los complementos con valor delimitativo. Veamos algunos de los ejemplos (los tres primeros provienen de la gramática de Vasil'eva-Švede, Stepanov, el último, de la tesis de Nowosadko y los demás, del estudio de Yllera):

${ }^{4}$ No son objetos de nuestro análisis diferentes tipos de simultaneidad establecidos por el esquema está cantando, es decir, coincidencia con el momento de la enunciación, extensión de carácter generalizador, etc.

${ }^{5}$ Según la estadística de Sedano (op. cit.: 264), el uso de pretérito al alcanzar sólo el $4 \%$ del total, es esporadico, lo que confirma las observaciones de los autores citados supra. No obstante, en nuestra opinión, este hecho no debería ser considerado como testimonio de la marginalidad sistemática de estuvo cantando. En el español actual la expresión del contenido 'duración limitada' mediante la perífrasis estar + gerundio tiene, en principio, carácter optativo, aunque hay casos de preferencia y cuasi obligación relacionados con las posibles diferencias de contenido marcadas por la construcción perifrástica y por la forma simple de pretérito (veáse a este respecto los ejemplos de Yllera, 1999: 3406). 
(1) ¿Viste lo que hizo? - No. - Le estuvo pasando billetitos toda la noche (J. Goytisolo).

(2) Yo ya voy al campo, ya no valgo; estuve yendo más de cuarenta años, sin dejar un día, hasta que me rendi (C.J. Cela).

(3) Estuve bailando media hora con él y te aseguro que no empalmo (J. Goytisolo).

(4) Estuve dándole vueltas a la cuestión (durante un tiempo).

(5) $Y$, durante un tiempo, los estuve observando.

(6) Estuvo durmiendo cuatro horas.

(7) Estuvieron discutiendo hasta altas horas de la noche.

(8) Hasta la madrugada estuvieron divirtiéndose.

(9) Estuvo buscándolo hasta que lo encontró.

(10) Toda la tarde estuvieron entrando visitas.

Como se ve, la construcción estuvo cantando está modificada mediante complementos que bien abarcan un período de tiempo (ejs. $1,3,4,5,6,10$ ), bien marcan un limite temporal $(7,8,9)$. En el ejemplo (2) la accion denotada por la perífrasis está sometida a una restricción doble: se indican tanto el lapso (más de cuarenta años) como el límite (hasta que me rendi) temporales.

En todos los ejemplos citados la perífrasis podría ser sustituida por la forma simple, lo que provocaría que dejasen de ser percibidos el desarrollo y el matiz durativo de la acción. No obstante, como sostiene Yllera (op. cit.: 3406- 3407), hay casos cuando resulta posible establecer la oposición entre las formas simple y perifrástica a base del rasgo [ \pm conclusión del proceso]. Según dicha autora, cuando el sintagma verbal tiene carácter más "estativo", los valores de la forma simple y de la perífrasis se aproximan (Durmió / Estuvo durmiendo cuatro horas). En cambio, cuando el sintagma verbal es, semánticamente, más "dinámico", la forma simple marca la conclusión del proceso (Arreglaron el tejado en cuatro horas), mientras que la perifrástica indica más bien el cese de éste y no su conclusión (Estuvieron arreglando el tejado cuatro horas [tal vez no lo acabaron]). En opinión de Yllera (ibíd.), de hecho, se contestan dos preguntas distintas: ¿En cuánto tiempo lo hizo? y ¿Cuánto tiempo estuvo haciéndolo?, lo que quiere decir que las formas simples exigen determinaciones temporales conclusivas o delimitadoras, mientras que las perífrasis se combinan con determinaciones no-conclusivas.

Sin negar la posibilidad de tal interpretación, y en primer lugar de las diferencias que aportan los complementos terminativos y cursivos, quisiéramos señalar que la lectura no-conclusiva no tiene carácter absoluto y la propia autora la formula en forma de una aserción limitada: tal vez no lo acabaron. Por otro lado, cabe subrayar que la conclusión de la acción está en una relación estrecha con el significado desinente del sintagma arreglar el tejado y con el sentido delimitador del complemento circunstancial en cuatro horas. El tiempo empleado, es decir, el pretérito (arreglaron), no desempeña en este caso papel decisivo, aunque participa en la presentación de la acción como concluida. 
En cambio, lo que no cabe duda es que el empleo del pretérito (tanto en su forma simple como en la construcción estar + gerundio) está vinculado con el concepto de 'limitación temporal de la acción realizada', incompatible (salvo los casos cuando se expresa 'habitualidad') con el copretérito: *Dormía / Estaba durmiendo cuatro horas o *Arreglaban / Estaban arreglando el tejado (en) cuatro horas.

\section{LOS ENFOQUES TEMPORAL Y ASPECTUAL DEL PRETÉRITO}

No obstante, algunos lingüístas (véase, p.ej., García Fernández, 1999) consideran que la diferencia entre el pretérito y el copretérito no es del tipo temporal, sino aspectual ${ }^{6}$. De acuerdo con este planteamiento se considera que el pretérito es exponente del aspecto perfectivo, mientras que el copretérito es portador del aspecto imperfectivo. Así, al comparar los ejemplos Ayer Juan estaba en Madrid y Ayer Juan estuvo en Madrid, García Fernández (op. cit.: 170) observa que mientras que en el primero, la acción puede ser prolongada hasta el momento de la enunciación, en el segundo, dicha extensión no es posible. Esto le permite sacar la siguiente conclusión (op. cit.: 170-171): el copretérito expresa el aspecto imperfecto (término del autor), porque no se sabe si la estancia de Juan ha acabado o no; en cambio, el pretérito es marca del aspecto perfectivo, porque "se afirma la situación completa", es decir, Juan no está en Madrid en el momento de la enunciación.

Con este motivo queríamos hacer tres observaciones.

Primero, en las lenguas que tienen el aspecto morfológico la imperfectividad no está relacionada con el hecho de saber o no si la acción ha terminado o no. Si se utiliza la forma del aspecto imperfectivo, tal como ocurre, p. ej., en ruso o en polaco, siempre se denota una acción no acabada, sin que sea importante que lo sepamos o no. El caso del copretérito castellano no es el mismo, porque no excluye del todo la posibilidad de la conclusión de la acción (de hecho sería más conveniente hablar de la anterioridad cronológica con respecto al origen).

Segundo, al analizar ejemplos semejantes a Ayer Juan estuvo en Madrid, podríamos adoptar otra perspectiva: la acción se percibe como perfectiva, porque tiene límite temporal. Tal como señala García Fernández (ibíd.), en el caso de estuvo la acción no puede ser prolongada hasta el momento de la enunciación ${ }^{7}$. Esto

${ }^{6}$ Curiosamente, se admite la definición del aspecto en términos temporales. Asi, García Fernảndez (1999: 170), siguiendo a Klein (1992), señala que el aspecto se refiere a "la relación no deíctica entre dos intérvalos de tiempo".

7 Fijemonos que al operar con conceptos tales como 'prolongación' o 'momento de la enunciación', en el fondo, el razonamiento del autor es más "temporal" que "aspectual". Sin descartar la evidente relación entre las categorías gramaticales tiempo y aspecto, no se debe olvidar que la 
ocurre, porque el pretérito siempre es anterior al origen siendo este último su límite fijo.

Por último, cabe señalar que si una acción aspectualmente perfectiva siempre tiene límite temporal (nos referimos al caso de las lenguas eslavas), no ocurre lo mismo al revés, es decir, una acción aspectualmente imperfectiva no excluye límites temporales. En español, el copretérito rara vez se combina con los complementos que expresen delimitación (véase supra) ${ }^{\mathrm{g}}$. En cambio, tanto en polaco como en ruso, las formas del aspecto imperfectivo son totalmente compatibles con complementos adverbiales que establecen límites temporales. En este sentido es significativa la no-coincidencia entre el uso del pretérito en la perífrasis estar + gerundio en los ejemplos (1)-(10) y el empleo de las formas del aspecto imperfectivo en las traducciones de las oraciones españolas al polaco o al ruso: en todos los casos el pretérito castellano sería traducido mediante las formas del aspecto imperfectivo?

\section{OBSERVACIONES FINALES}

En español el pretérito es compatible con la construcción perifrástica estar + gerundio que, según algunos lingüistas, funciona como marca del aspecto imperfectivo. En opinión de otros, si no toda la perífrasis, al menos el gerundio es exponente del contenido aspectual 'imperfectividad'. Ahora bien, si se admite que el pretérito es portador de "perfectividad aspectual" , resulta que la estructura semántica de la perífrasis sería: "perfectividad" (pretérito) + "imperfectividad"

esencia del aspecto consiste en la expresión de la conclusión o no-conclusión real (es decir, no sólo "temporal") de la acción. Si un polaco dice Zjadtem paellę (esp. Comí / He comido paella), emplea la forma perfectiva, porque el plato está vacío. Si no fuese así (todavía queda paella), un hablante polaco emplearía la forma del aspecto imperfectivo (Jadtem paellę). Lógicamente, una acción concluida como proceso tiene al mismo tiempo límite temporal. Es por eso porque en la mayoría de los casos a las formas del aspecto perfectivo en polaco o en ruso les corresponden las formas del pretérito en español o en otras lenguas romảnicas.

${ }^{8}$ En los ejemplos comentados por García Fernández (op. cit.: 173) la explicación del uso del copretérito con los complementos adverbiales en función de delimitadores temporales se lleva a cabo mediante conceptos tales como 'habitualidad', 'macroevento' y 'microevento'. Cabe apuntar que la noción de 'habitualidad' está relacionada más bien con el Aktionsart que con el aspecto.

${ }^{9}$ Por supuesto, las categorías de las lenguas eslavas no suelen ser utilizadas para explicar el funcionamiento de las categorías gramaticales del español. El polaco y el castellano son sistemas autónomos y en este sentido el procedimiento consistente en recurrir a una lengua para explicar el funcionamiento de otra siempre va a tener validez limitada. No obstante, creemos que en este caso concreto las referencias a las lenguas eslavas deberían ser consideradas como justificadas, puesto que dichos idiomas cuentan en sus sistemas gramaticales con la categoría de aspecto expresada morfológicamente. 
(gerundio) ${ }^{10}$. Sería poco probable que la suma estos componentes diera como resultado final el contenido "imperfectividad".

En cambio, si se considera que el rasgo del pretérito es 'limitación temporal' (en nuestra opinión, esta característica le es inherente, puesto que incluso las llamadas acciones puntuales tienen límites temporales), no hay obstáculos para reconocer que en el caso del esquema estuvo cantando se trata de 'una acción en desarrollo limitada en el tiempo" ". Recordemos que en las lenguas que tienen en sus sistemas gramaticales la categoría de aspecto expresada mediante recursos morfológicos el rasgo 'limitación temporal' es perfectamente compatible con la característica aspectual 'imperfectividad' (algo parecido ocurre en el caso de la construcción estuvo cantando). Lo que cabe subrayar, en cambio, es que desde el punto de vista del aspecto, una acción no puede ser al mismo tiempo "perfectiva" e "imperfectiva".

\section{BIBLIOGRAFİA}

Fernàndez Laguinilla, M. (1999), Las construcciones de gerundio, en I. Bosque, V. Demonte (eds.), Gramática descriptiva de la lengua española, RAE, Espasa Calpe, Madrid, v. 2, 3443-3503.

G a r c í a Fe r nả n d e z, L. (1999), Sobre la naturaleza de la oposición entre pretérito imperfecto y pretérito perfecto simple, LEA, XXI/2, 169-188.

K l e i n, W. (1992), The Present Perfect Puzzle, Language, 68: 3, 525-552.

Neustroeva, G.K. (1997), Teoreticeskaja grammatika portugal'skogo jazyka. Morfologija, Izdatel'stvo S.-Peterburgskogo Universiteta, Sankt-Peterburg.

$\mathrm{N}$ ow os a d k o, A. (2000), Las perífrasis verbales en español y en francès. Aproximación al análisis comparado, tesis de licenciatura inédita defendida en el Departamento de Filología Romãnica de la Universidad de Lódź.

R o j o, G., V e i g a, A. (1999), El tiempo verbal. Los tiempos simples, en I. Bosque, V. Demonte (eds.), Gramática descriptiva de la lengua española, RAE, Espasa Calpe, Madrid, v. 2, 2867-2934.

$\mathrm{S}$ ed a n o, M. (2000), La perífrasis de gerundio en Caracas y otras ciudades hispanohablantes, NRFH, t. XLVIII, núm. 2, 253-274.

Sła wo m i r s ki, J. (1983), La posición del aspecto en el sistema verbal español, R.S.E.L, XIII, 1, 91-119.

V a s il ' e va - S' ve de, O.K., S t e p a n ov, G.V. (1972), Teoreticeskaja grammatika ispanskogo jazyka. Morfologija i sintaksis častej reči, Izdatel'stvo „Wyš̌aja Skola”, Moscú.

Y 11 e r a, A. (1999), Las perifrasis verbales de gerundio y participio, en I. Bosque, V. Demonte (eds.), Gramática descriptiva de la lengua española, RAE, Espasa Calpe, Madrid, v. 2, 3391 3441 .

${ }^{10}$ Somos conscientes de que se trata de una visión simplificada que, p. ej., no toma en consideración la "estatividad" semântica del verbo auxiliar. Sin embargo, nuestro objetivo es conseguir mayor claridad.

${ }^{11}$ Ésta, de hecho, aunque adoptada posiblemente desde una perspectiva un tanto diferente, es la postura admitida también por Yllera (1999: 3405). 